\title{
UV ile sertleşen hibrid kaplamalarla alüminyum levhaların yüzey özelliklerinin iyileștirilmesi
}

\author{
İlyas KARTAL ${ }^{*}$ \\ Marmara Üniversitesi, Teknoloji Fakültesi, Metalurji ve Malzeme Mühendisliği, Göztepe Kampüsü, \\ Istanbul. \\ Geliş Tarihi (Recived Date): 28.09.2017 \\ Kabul Tarihi (Accepted Date): 10.11.2017
}

\section{Özet}

Alüminyum birçok üstün özelliklere sahip olmasına rağmen kolayca çizilme ve aşınma, çok çabuk korozyona uğrama, kir ve leke tutma gibi bazı dezavantajlara sahiptir. Alüminyum yüzeyine hibrid kaplama yapılarak aşınmaya, çizilmeye, korozyona, kir ve lekeye karşı dirençli hale getirmek aynı zamanda görsel ve dekoratif özellikler kazandırmak mümkündür. Bu çalışmada yüksek miktarda flor içeren yapılar ile silisyum içerikli yapılarla reaksiyona sokularak flor içerikli inorganik faz elde edildi. Hibrid yapının organik kısmı ise epoksi akrilat, hekzan diol diakrilat ve UV başlatıcıdan oluştu. Organik ve inorganik kısımların manyetik karıştırıcı yardımıyla homojen bir şekilde karıştırılmasıyla flor içeren hibrid kaplama formülasyonları yüzeye uyguland. Farklı içeriklere sahip formülasyonlar UV ışınlarıyla sertleştirilerek yüzeylerin kaplama performanslarl incelendi. Alüminyum levha yüzeyleri UV ışınlarıyla sertleşebilen flor içerikli hibrid malzemeyle kaplanarak aşınmaya, sürtünmeye, çizilmeye, korozyona, kir ve lekelere karşı dirençli hale getirildi. Bununla beraber yüksek parlaklıkta görsel ve dekoratif özelliklere sahip bir yüzey elde edildi.

Anahtar Kelimeler: Alüminyum, florosilan, UV ile sertleşebilen kaplamalar.

\section{Improvement of surface properties of aluminum sheets with UV curable hybrid coatings}

\begin{abstract}
Although aluminum has many superior properties, it has some disadvantages such as scratching and abrasion, very quick corrosion, dirt and stain retention. It is possible to make the aluminum surface resistant to abrasion, scratching, corrosion, dirt and stains
\end{abstract}

* İlyas KARTAL, ilyaskartal@marmara.edu.tr, http://orcid.org/0000-0001-9677-477X 
by giving a hybrid coating at the same time to give visual and decorative features. In this study, fluorine containing inorganic phase was obtained by reacting high amounts of fluorine containing structures with silicon containing structures. The organic part of the hybrid structure consisted of epoxy acrylate, hexane diol diacrylate and UV initiator. Hybrid coating formulations containing fluorine were applied to the surface by mixing the organic and inorganic parts homogeneously with a magnetic stirrer. The formulations with different contents were hardened by $U V$ rays and the coating performance of the surfaces was examined. Aluminum sheet surfaces were coated with fluoride-containing hybrid material which was hardened by UV rays and made resistant to abrasion, rubbing, scratching, corrosion, dirt and stains. However, a surface with high visibility and decorative features was obtained.

Keywords: Aluminum, fluoro silane, UV curable coatings.

\section{Giriş}

Dünyada en fazla mevcut olan metaller sıralamasında ikinci sırayı alan alüminyum hafif metal sınıfından bir element olması, yüksek elektrik ve 1sı iletkenliği, kolay işlenebilirlik, soğuk ve sıcak şekillenebilirlik gibi özellikleri nedeniyle kullanım alanı yaygın olan bir elementtir. Benzer özelliklerdeki metallere göre kısmen daha ucuz olması ve kolay temin edilebilmesi alüminyumu tercih edilir kılmaktadır [1-2].

Alüminyum birçok üstün özelliklerinden dolayı otomotiv endüstrisinden elektronikbilgisayar endüstrisine, makine ve imalat endüstrisinden kimya ve gıda endüstrisine kadar günlük yaşamın her alanında oldukça geniş bir kullanım alanı vardır. Son yıllarda, alüminyum ve alaşımları yüksek mukavemet ve düşük özgül ağırlığa sahip olduklarından uzay, havacılık ve otomotiv endüstrisinin odağı haline gelmiştir [3].

Alüminyum birçok üstün özelliklere sahip olmasına rağmen kolayca çizilme ve aşınma, çok çabuk korozyona uğrama, kir ve leke tutma gibi bazı dezavantajlara sahiptir. Alüminyum yüzeyine hibrid kaplama yapılarak aşınmaya, çizilmeye, korozyona, kir ve lekeye karşı dirençli hale getirmek aynı zamanda görsel ve dekoratif özellikler kazandırmak mümkündür [4-5].

Kaplama uygulamalarında florlu silan içeren bileşiklerin kullanımı son yıllarda sıklıkla çalışılmaktadır. Florun yapıya sağladığı hidrofobluk, yüzeyde kir-su-leke tutmama, atmosfer direnci, sürtünme katsayısının düşük olması gibi özellikleri sebebiyle bu tür kaplamalar oldukça caziptir [6-9].

Farklı yapılar üzerine floropolimer esaslı hibrid kaplama çalışmaları uzun yıllardır devam etmektedir. Bu çalışmalardan birinde sol-jel tekniği kullanılarak epoksi bazlı oligomer, silanlı yapılar, reaktif çözücüler ve fotobaşlatıcı kullanılarak UV ile sertleşebilen organik-inorganik hibrid kaplamalar hazırlanmıştır. Sol-gel karışımları ilavesiyle farklı kompozisyonlarda organik-inorganik hibrid kaplama formülasyonları havacılıkta kullanılan alüminyum levha yüzeylerine uygulanmış ve kaplamanın fizikselkimyasal özellikleri incelenmiştir. Bu çalışma ile yapışma özellikleri, mekanik özellikleri ve korozyon direnci gibi yüzey özelliklerinin performansının arttığı ve kaplama malzemesi olarak kullanılabileceği öngörülmüştür [10]. Diğer bir çalışmada [11] alüminyum üzerine polimerik sol-gel kaplamalar uygulamış ve korozyon direnci 
arttırılmış hidrofobik yüzeyler elde etmişlerdir. Bunlarla beraber galvanize olmuş çelik üzerine floropolimer kaplama uygulamaları [12], metalleri UV ışınlarıyla sertleşebilen kaplamalar ile korozyona karşı koruma uygulamaları [13], magnezyum alaşımı üzerine flor içeren kaplama uygulamaları [14] gibi literatürde birçok çalışma vardır.

Bu çalışmada, günümüzde geniş bir uygulama alanı bulunan alüminyum levhaların yüzeyini, UV 1şınlarıyla sertleşebilen flor içerikli hibrid kaplama formülasyonlarıyla kaplayarak parlaklık, hidrofobik yüzey, aşınma, sürtünme, çizilme, görsel ve dekoratif görünüm gibi yüzey özelliklerinin geliştirilmesi ile organik çözücülere, kir ve lekelere karşı direncinin arttırılması, yüksek parlaklıkta görsel ve dekoratif özelliklere sahip bir yüzey elde edilmesi amaçlanmıştır.

$\mathrm{Bu}$ amaçla yüksek miktarda flor içeren yapılar ile silisyum içerikli yapılarla reaksiyona sokularak flor içerikli inorganik faz elde edildi. Hibrid yapının organik kısmı ise epoksi akrilat, hekzan diol diakrilat ve UV başlatıcıdan oluşmuştur. Organik ve inorganik kısımlar homojen bir yapı haline getirilerek flor içeren hibrid kaplama formülasyonları yüzeye uygulanmıştır. Farklı flor ve silisyum içeriklerine sahip formülasyonlar UV 1şınlarıyla sertleştirilerek yüzeylerin kaplama performansları incelendi.

\section{Deneysel çalışmalar}

\subsection{Malzemeler}

Reaktif reçine; Bisfenol A gliserolat (1 glycerol/phenol) diakrilat, reaktif çözücü; 1,6 Hekzandiol diakrilat, etanol, 2,2,3,3,4,4,5,5,6,6,7,7-Dodecafloro-1,8-oktandiol, 3Izosiyanato propiltrimetoksi silan, metakrioiloksipropil trimetoksisilan (MEMO) ve Tetraetilortosilikat (TEOS) Sigma Aldrich firmasından tedarik edildi. UV başlatıcı olarak Igracure 184 (IRG 184) Ciba Specialty Chemicals'dan temin edildi. ptoluensülfonikasit (PSTA) ise Merck'den tedarik edildi. Alüminyum levhalar (1050 seri alaşımlı) yerel tedarikçilerden satın alındı.

\section{2. Üretan esaslı hibrid kaplamanın hazırlanmast}

Ilk olarak 2,2,3,3,4,4,5,5,6,6,7,7-Dodecafloro-1,8-octanediol ile 3-Izosiyanato propiltrimetoksi silan $60^{\circ} \mathrm{C}$ sicaklıkta azot atmosferi altında 24 saat süresince $(\% 1$ oranında T12 katalizörü ilavesiyle) reaksiyona sokularak üretan modifiye flor içerikli yapı sentezlendi. Reaksiyon takibi FT-IR spektrumunda $2275 \mathrm{~cm}-1$ 'de -NCO pikinin değişimiyle takip edildi (Şekil 1). İkinci aşamada silanla sonlanmış üretan içine TEOS, MEMO, etanol ve su ilave edilerek hidroliz ve polikondenzasyon reaksiyonu ile UV ile sertleşebilen inorganik faz elde edilmiştir. Üretan esaslı inorganik faz içeren kaplamanın elde etme aşamaları Şekil 2'de gösterilmiştir.

\subsection{Hidroliz ve kondenzasyon reaksiyonu}

Üretan modifiye perfloro alkoksi silan, tetraetilortosilikat (TEOS), metakrioiloksipropil trimetoksisilan (MEMO), etanol, su ve p-toluensülfonikasit (kataliz) oluşan karışım oda sicaklığında 12 saat boyunca azot atmosferi altında karıştırıldı. $\mathrm{H}_{2} \mathrm{O} / \mathrm{Si}$ oranı $\mathrm{r}=3$ olacak şekilde hesapland. 


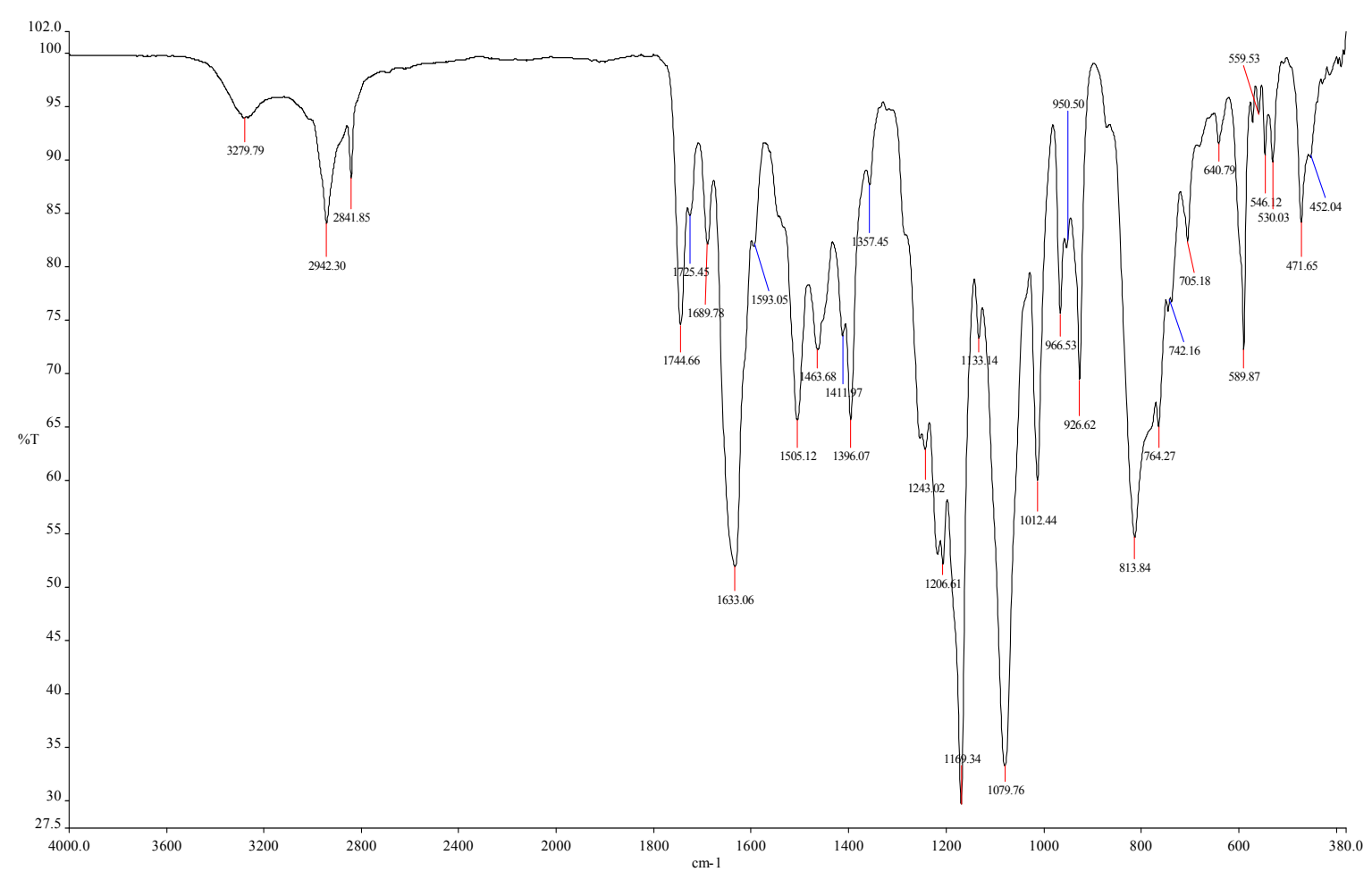

Şekil 1. Monomerlerin reaksiyonu sonras $2275 \mathrm{~cm}^{-1}$ 'de kaybolan -NCO pikleri.

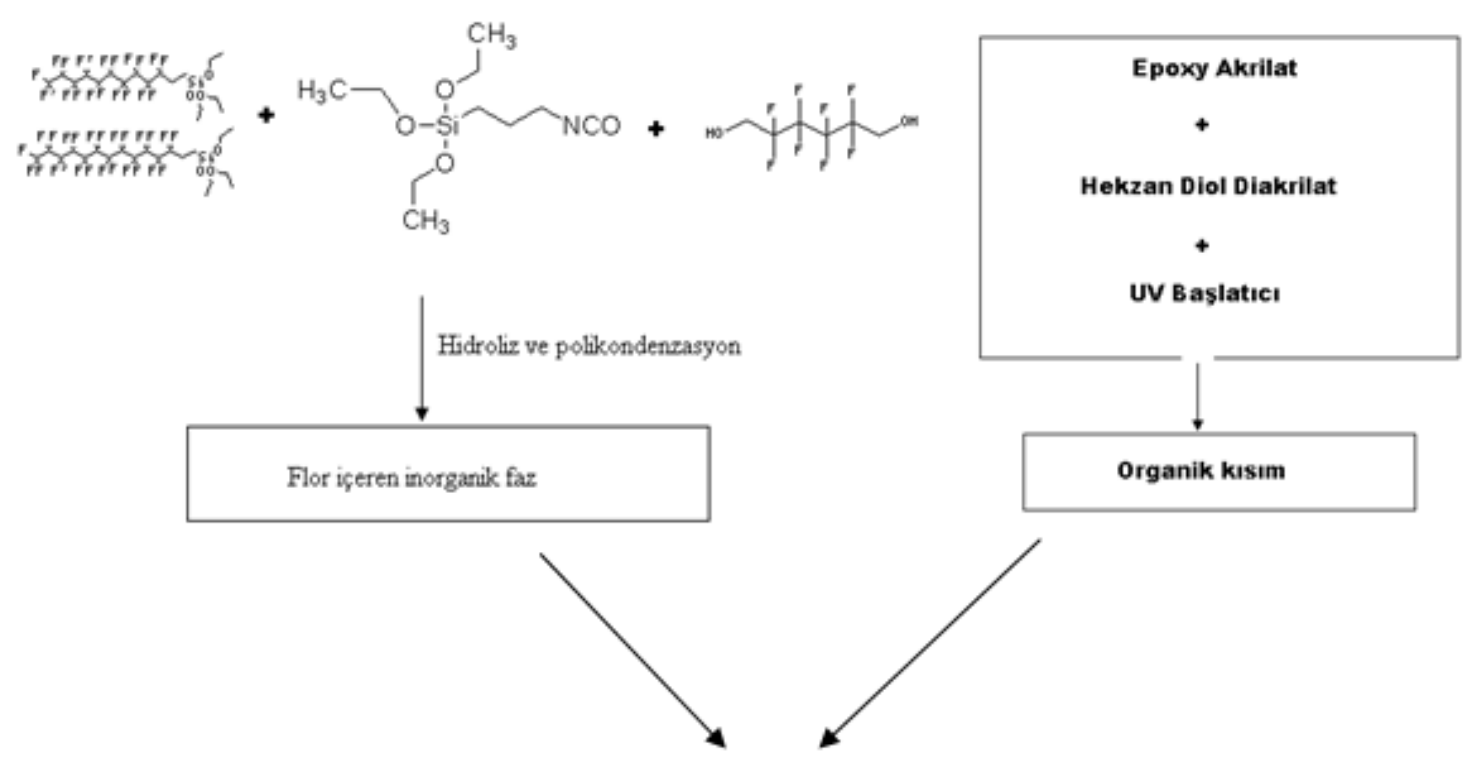

Organik ve inorganik kısım homojen olarak karıstırıldıktan sonra hibrit yapı, UV ile sertlestirme

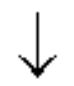

Üretan Esaslı Flor İçeren Hibrid Kaplama

Şekil 2. Hibrid formülasyon hazırlama aşamaları. 


\subsection{Film formülasyonlarının hazırlanması}

Şekil 3'de şematik olarak gösterildiği gibi epoksi akrilat, HDDA ve UV başlatıcıdan oluşan organik kısma, flor içeren üretan, TEOS, MEMO içeren inorganik kısım farklı oranlarda (ağırlıça \%2.5 - \%5, \%7.5 - \%10 - \%15 ve \%20) ilave edilmesiyle UV ile sertleşebilen hibrid kaplama formülasyonları elde edilmiştir. Her bir karışım için 25 ml'lik beherlerde şeffaf ve homojen bir yapı elde edildi. Bu esnada oluşabilen hava kabarcıkları vakum etüvde $35^{\circ} \mathrm{C}^{\prime}$ de $5-10$ dakika kadar tutularak giderildi. Formülasyonlar alüminyum levhalar üzerine homojen bir şekilde dörtkenarlı aplikatörle uygulandı, sonra da UV ışınları yardımıyla sertleştirildi.
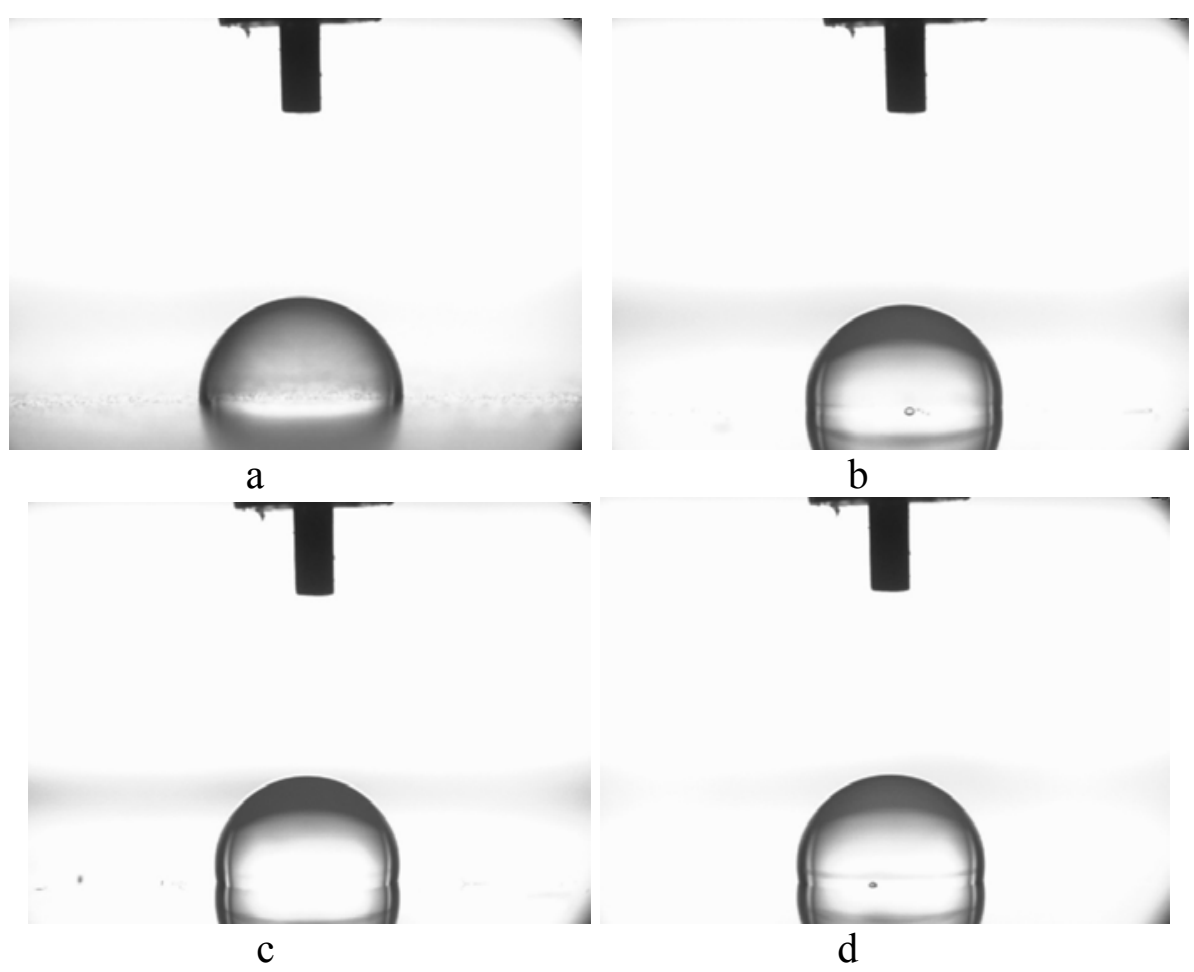

Şekil 3. Yüzeylerden elde edilen tipik temas açı görüntüleri a. Kaplanmamış Al yüzeyi b. Sadece organik kaplama yapılan yüzey c. \%5 inorganik kısım içeren yüzey d. \%15 inorganik kısım içeren yüzey.

\subsection{Karakterizasyon}

Her bir formülasyon karışımları alüminyum levhalar üzerine $30 \mu \mathrm{m}$ 'lik aplikatör yardımıyla kaplandı. Bu iş için tezgah tipli bir UV sertleştirme cihazı (Raycon, 120 $\mathrm{w} / \mathrm{cm}, \lambda_{\max }=365 \mathrm{~nm}$, orta basınçlı civa UV lambası) kullanıldı. TS 1398 standardına göre hazırlanan numunelerin çekme deneyi, Zwick Z010 üniversal çekme cihazında, 5 $\mathrm{mm}$ /dakika çekme hızı kullanılarak yapılmıştır.

Kaplamanın özellikleri aşağıdaki test metotlarına göre belirlenmiştir:

Parlaklık testi (gloss)

Yapışma testi (cross cut)

Kalem sertlik (pencil hardness)

Solvent direnci

Kirlenme

Temas açıs1
ASTM D-5380

DIN 53151

ASTM D-3363

ASTM D-5402

ASTM C-1378

ASTM D7490 - 08 


\section{Sonuçlar ve tartışma}

Epoksi akrilat esaslı üretan modifiye perfloro alkoksi silan içeren hibrit kaplamanın kaplama performansı farklı karakterizasyon yöntemleriyle test edildi ve yüzey özellikleri incelendi.

Hibrid kaplamalara yapılan fiziksel test sonuçları Tablo 1'de gösterilmiştir. Yapılan kalem sertlik testi tüm kaplamalar için $6 \mathrm{H}$ kalem sertliği değerine sahip olduğunu göstermektedir ki, bu sertlik değeri bu yöntemle elde edilen en yüksek sertlik değeridir. Kaplanan malzemenin, altlık malzemeye yapışma karakteristiği hakkında bilgi veren Cross-cut testine göre organik yapı ile kaplanan yüzeyde $\left(\begin{array}{l}\% \\ \%\end{array}\right)$ test sonrası çok iyi yapışma olmuş ve bu yapışmanın \% 10'a kadar aynı kaldı. \% 10 inorganik yapı içeren kaplamalarda ise kısmi dökülme olmuş, \% 15 ve \% 20'de ise ölçüm yapılamamıştır. Buradaki hibrid kaplamada çok yüksek flor oranı olması sebebiyle yapışma olmadığ1 düşünülmektedir. Yine tüm kaplamalara metil etil keton (MEK) ile ovma testi yapılmış ve gidiş geliş bir çevrim olacak şekilde, 500'den daha fazla çevrimde ovma yapılmasına rağmen kaplama yüzeyinde herhangi bir değişim olmamıştır. Glosmetre ile 600 de yapılan parlaklık ölçümü sonuçlarına göre yüzeyi kaplanmamış alüminyum yüzeyinin değerinin ise 51 olduğu tespit edilmiştir. Hibrid kaplamanın parlaklık değerini yaklaşık 2 kat arttırdığ 1 ortaya çıkmıştır. Florosilan içeriğinin artmasıyla kaplama parlaklığı iki kat bir artış göstermiştir.

Tablo 1. Hibrid kaplamanın fiziksel özellikleri.

\begin{tabular}{cccccc}
\hline $\begin{array}{c}\text { Hibrid Numune } \\
\text { İçeriği }\end{array}$ & $\begin{array}{c}\text { Kalem } \\
\text { Sertliği }\end{array}$ & $\begin{array}{c}\text { Temas } \\
\text { Açısı }(\mathrm{Su})\end{array}$ & $\begin{array}{c}\text { Cross } \\
\text { Cut }\end{array}$ & $\begin{array}{c}\text { MEK } \\
\text { Rub Testi }\end{array}$ & $\begin{array}{c}\text { Parlaklık } \\
60^{\circ}\end{array}$ \\
\hline$\% 0$ & $6 \mathrm{H}$ & 67 & 0 & $>500$ & 92 \\
$\% 2.5$ & $6 \mathrm{H}$ & 72 & 0 & $>500$ & 93 \\
$\% 5$ & $6 \mathrm{H}$ & 74 & 0 & $>500$ & 95 \\
$\% 7.5$ & $6 \mathrm{H}$ & 76 & 0 & $>500$ & 99 \\
$\% 10$ & $6 \mathrm{H}$ & 81 & 1 & $>500$ & 101 \\
$\% 15$ & $6 \mathrm{H}$ & 84 & - & $>500$ & 101 \\
$\% 20$ & $6 \mathrm{H}$ & 88 & - & $>500$ & 94 \\
\hline
\end{tabular}

Bir katı yüzeyi ile temastaki bir sıvı yüzeyi arasında oluşan açı temas açısı olarak adlandırılır. Temas açısı $90^{\circ}$ 'den büyük ise yüzey hidrofobik özelliktedir. Flor ve silisyum içeriğinin artması temas açısında artmaya neden olduğu birçok araştırmacı tarafından ispatlanmıştır [15]. Alüminyum yüzeyine yapılan kaplama içerisinde inorganik kısmın oranı arttığında temas açısı değerinde artış gözlenmiş olup hidrofobik özelliklere yakın bir yüzey elde edildiği temas açısı değer ve görüntülerinden de anlaşılmaktadır. Şekil 3'de kaplama yüzeylerinde su ile ölçülen temas açı görüntüleri verilmiştir.

Farklı kirlilik ajanları ile hibrid kaplamalara kirlenme testi yapılmış olup sonuçlar Tablo 2'de verilmiştir. Kirlilik ajanları pipet ile kaplama yüzeylerine damlatılarak tanımlanan temas süresi sonrasında su ile temizlendi ve kaplama yüzeylerindeki değişimler incelendi. Yüzeyi kaplanmamış olan alüminyum yüzeyine yapılan kirlenme testi sonuçlarına göre bütün kirlilik ajanlarından etkilendiği gözlemlenmiştir. Sadece organik kaplamalı yüzey kısmi etkilenme olmuş, florosilan içeriğine sahip yüzeyler bütün kaplama yüzeyleri kirlenme ajanlarına karşı kusursuz bir kirlenme direnci göstermiştir. 
Tablo 2. Hibrid kaplamalara yapılan kirlenme testi sonuçları ${ }^{\dagger}$

\begin{tabular}{ccccccccc}
\hline $\begin{array}{c}\text { Kirlilik Ajanı -Temas } \\
\text { Süresi }\end{array}$ & $\begin{array}{c}\text { Kaplanmamiş Al } \\
\text { Yüzeyi }\end{array}$ & $\% 0$ & $\% 2.5$ & $\% 5$ & $\% 7.5$ & $\% 10$ & $\% 15$ & $\% 20$ \\
\hline $\begin{array}{c}\text { Cay } \\
16 \text { saat }\end{array}$ & 4 & 6 & 7 & 7 & 7 & 7 & 7 & 7 \\
$\begin{array}{c}\text { Kahve } \\
16 \text { saat }\end{array}$ & 3 & 6 & 7 & 7 & 7 & 7 & 7 & 7 \\
$\begin{array}{c}\text { Asetik Asit, \% } 30 \\
10 \text { dakika }\end{array}$ & 5 & 7 & 7 & 7 & 7 & 7 & 7 & 7 \\
$\begin{array}{c}\text { NaOH, \% 25 } \\
10 \text { dakika }\end{array}$ & 5 & 7 & 7 & 7 & 7 & 7 & 7 & 7 \\
$\begin{array}{c}\mathrm{H}_{2} \mathrm{O}_{2}, \% 20 \\
10 \text { dakika }\end{array}$ & 5 & 7 & 7 & 7 & 7 & 7 & 7 & 7 \\
\hline $\begin{array}{l}\text { Tirilenme testi değerlendirmesi 1: Beyaz tortu; 2: Koyu kahverengi leke; 3: Açılk kahverengi leke; 4: Sarı leke; 5: Beyaz kenar; 6: } \\
\text { Uçuk kenar; 7: Değişiklik yok }\end{array}$ & & & & & & &
\end{tabular}

Teflon kalıba dökülerek elde edilen serbest filmlerin çekme ve darbe deneyi sonuçları Tablo 3'de verilmiştir. Kaplama içerisindeki inorganik kısım oranı artması ile çekme mukavemeti ve elastisite modülü değeri azalmıştır. Izod darbe mukavemeti \%7.5 inorganik yapı ilave edilen numuneye kadar artmış, \%10 ve daha fazla inorganik yap1 içeren numunelerde ise düşmüştür.

Tablo 3. Çekme ve darbe deneyi sonuçları

\begin{tabular}{cccc}
\hline $\begin{array}{c}\text { Hibrid Numune } \\
\text { İceriği }\end{array}$ & $\begin{array}{c}\text { Çekme Mukavemeti } \\
\text { MPa }\end{array}$ & $\begin{array}{c}\text { Elastik Modülü } \\
\text { MPa }\end{array}$ & $\begin{array}{c}\text { Izod Darbe } \\
\text { Mukavemeti kJ } / \mathrm{m}^{2}\end{array}$ \\
\hline$\% 0$ & 38 & 522 & 8.1 \\
$\% 2.5$ & 37 & 510 & 9.9 \\
$\% 5$ & 35 & 502 & 11.4 \\
$\% 7.5$ & 33 & 496 & 12.6 \\
$\% 10$ & 29 & 488 & 11.1 \\
$\% 15$ & 28 & 471 & 6.9 \\
$\% 20$ & 26 & 459 & 6.0 \\
\hline
\end{tabular}

Alüminyum levhanın yüzeylerine yapılan kaplama ile yüzey özelliklerinin geliştirilebildiği yapılan testler sonucunda ortaya çıkmıştır. FT-IR analizinde formülasyonlarda-NCO piklerinin reaksiyon sonrasında kaybolmasiyla üretan modifiye bir kaplama olduğu tespit edilmiştir. Hibrid kaplama yapılan Alüminyum levha yüzeyi $6 \mathrm{H}$ kalem sertlik değerine sahip olup MEK ile yapilan ovma testinde 500 cevrim sonunda yüzey özelliklerinde bir değişme olmadığ 1 görülmüştür. Parlaklık değerinde iki kat kadar bir artış gözlemlenmiştir. Kirlilik ajanları ile yapılan kirlenme testinde, kaplanmış levhaların leke tutmama özelliklerinin mükemmel olduğu görülmüştür. Temas açışı ölçümlerinden çıkan sonuca bakıldığında, kaplamanın hidrofob özellik göstermediği görülmektedir. Kaplama malzemesinin yüzeyle yaptığı bağın iyi olduğu yapışma testi sonuçlarından anlaşılmaktadır.

Alüminyum levhanın parlaklığının iki kat artırılarak görsel ve dekoratif özellikleri geliştirilmiştir. Çizilmeye karşı dayanıklı olması, leke tutmaması ve mevcut lekenin yüzeyden kolayca temizlenebilmesi sebebiyle diş ortamlarda rahatlıkla kullanılabilecek ve çözücülere karşı dayanıklı mevcut temizlik malzemeleri ile çizilmeden ve çözülmeden temizlenebilen bir kaplama geliştirilmiştir. 


\section{Kaynaklar}

[1] Dursun, T. ve Soutis, C., Recent developments in advanced aircraft aluminium alloys, Materials and Design, 56, 862-871, (2014).

[2] Baburaja, K., Subbaiah, K.V. ve Kalluri, R., Hybrid materials of aluminium, Materials Today: Proceedings Part B, 3, 10, 4140-4145, (2016).

[3] Maung K.N., Yoshida, T., Liu, G., Lwin, C.M. ve Hashimoto, S., Assessment of secondary aluminum reserves of nations, Resources, Conservation and Recycling, 126, 34-41, (2017).

[4] Hofacker, S., Mechtel, M., Mager, M. ve Kraus, H., Sol-Gel: A new tool for coatings chemistry, Progress In Inorganic Coatings, 45, 2-3, 159-164, (2002).

[5] Livage, J., Sol-Gel processes, Current Opinion in Solid State and Materials Science, 2, 2, 129-275, (1997).

[6] Drobny, J.G., Blends and composites based on fluoropolymers, Macromol. Symp., 170, 1, 149-156, (2001).

[7] Anton, D., Surface fluorinated coatings, Advanced Materials 10, 15, 1197 1205, (1998).

[8] Imae, T., Fluorinated polymers, Current Opinion in Colloid and Interface Science, 8, 3, 307-314, (2003).

[9] Bongiovanni, R., Malucelli, G., Sangermano, M. ve Priola, A., Properties of UV-curable coatings fluorinated acrylics structures, Progress in Organic Coatings 36, 1-2, 70-78, (1999).

[10] Du, Y., Damron, M., Tang, G., Zheng, H., Chu, C.J. ve Osborne, J., Inorganic/organic hybrid coatings for aircraft aluminum alloy substrates, Progress in Organic Coatings, 41, 4, 226-232, (2001).

[11] Conde, A., Durán, A. ve Damborenea, J.J., Polymeric Sol-Gel coatings as protective layers of aluminium alloys, Progress in Organic Coatings, 46, 4, 288-296, (2003).

[12] Barbucci, A., Pedroni, E., Perillon, J.L. ve Cerisola, G., Organic coatings for pre-treated galvanized steel technology, Progress in Organic Coatings, 29, 1-4, 7-11, (1996).

[13] Malucelli, G., Gianni, A.D., Deflorian, F., Fedel, M. ve Bongiovanni, R., Preparation of ultraviolet-cured nanocomposite coatings for protecting against corrosion of metal substrates, Corrosion Science, 51, 8, 1762-1771, (2009).

[14] Zhong, X., Li, Q., Hu, J. ve Lu, Y., Characterization and corrosion studies of ceria thin film based on fluorinated AZ91D magnesium alloy, Corrosion Science, 50, 8, 2304-2309, (2008).

[15] Hougham, G.G., Cassidy, P.E., Johns, K. ve Davidson, T., Fluoropolymers 2, Kluwer Academic Publishers, New York, (2002). 